\title{
Article \\ Energy Evolution and Damage Mechanism of Fractured Sandstone with Different Angles
}

\author{
Xinwei Li ${ }^{1,2} \mathbb{D}$, Zhishu Yao ${ }^{1,2, * \mathbb{D}}$, Xiaohu Liu ${ }^{1,2}$ and Xianwen Huang ${ }^{1,2}$ \\ 1 School of Civil Engineering and Architecture, Anhui University of Science and Technology, \\ Huainan 232001, China; xwli@aust.edu.cn (X.L.); 2020134@aust.edu.cn (X.L.); \\ 162100003@stu.just.edu.cn (X.H.) \\ 2 Research Center of Mine Underground Engineering of Ministry of Education, \\ Anhui University of Science and Technology, Huainan 232001, China \\ * Correspondence: zsyao@aust.edu.cn; Tel.: +86-139-5541-8561
}

Citation: Li, X.; Yao, Z.; Liu, X.; Huang, X. Energy Evolution and Damage Mechanism of Fractured Sandstone with Different Angles. Energies 2022, 15, 1518. https:// doi.org/10.3390/en15041518

Academic Editors: Pavel A. Strizhak, Nikolaos Koukouzas and Michael Kühn

Received: 22 January 2022

Accepted: 16 February 2022

Published: 18 February 2022

Publisher's Note: MDPI stays neutral with regard to jurisdictional claims in published maps and institutional affiliations.

Copyright: (c) 2022 by the authors. Licensee MDPI, Basel, Switzerland. This article is an open access article distributed under the terms and conditions of the Creative Commons Attribution (CC BY) license (https:// creativecommons.org/licenses/by/ $4.0 /)$.

\begin{abstract}
To explore the influence of crack angle on the mechanical properties, energy evolution, and damage evolution of sandstone, uniaxial loading tests were conducted on sandstones with different crack angles. Through the stress-strain curve, the influence of the crack angle on the mechanical properties was analyzed. Based on energy theories and principles, the influence of crack angle on the energy conversion mechanism was analyzed. Based on crack angle and dissipated energy, a damage model considering the initial damage to the fractured sandstones was established. The following conclusions were drawn: (1) The strength and elastic modulus of sandstone decrease with an increase in crack angle, and Poisson's ratio increases with an increase in crack angle; prefabricated cracks affect the crack initiation position, and accelerate the formation of fracture surfaces. (2) The stress-strain curve was divided into compaction stage, elastic stage, yield stage, and failure stage. The larger the crack angle, the longer the yield stage and the shorter the failure stage. (3) At the peak point, the elastic energy, dissipated energy, and input energy of fractured sandstone always decrease with an increase in crack angle; the energy consumption ratio increases with an increase in crack angle; and the energy storage ratio decreases with an increase in crack angle. (4) The damage variable shows a trend of slow accumulation-steady accumulation-rapid accumulation; the crack angle affects the initial damage of the specimen, and the dissipated energy affects the variation trend of the damage variable.
\end{abstract}

Keywords: crack angle; mechanical properties; failure mode; energy evolution; damage

\section{Introduction}

In underground engineering, there are various levels of defects within the rock mass, such as faults, cracks, holes, voids, gaps, pores, etc. These defects are present in rock bodies in different spatial scales and forms. Cracks and macrocracks in rock mass have a noticeable impact on the strength and stability of surrounding rocks, especially on the construction and service safety of underground engineering [1-5]; thus, it is particularly important to study the deformation and failure mechanism of fractured rock. To date, some researchers have conducted substantial basic research on fractured sandstone, analyzing the influence of crack shape [6], crack length [7], crack angle [8], and crack location [9], on the deformation and failure characteristics of rock. Some achievements have been obtained, but most of these have been confined to the analysis of experimental phenomena, so the mechanisms of deformation and failure require further study.

The process of rock deformation and failure is a process of energy input, accumulation, dissipation and release; therefore, the research on the failure mechanism of rock is mostly based on thermodynamic theory [10-13]. A large number of experiments have been carried out to study the energy conversion mechanism in the processes of rock deformation and failure. Zhang et al. [14] conducted uniaxial loading tests on fractured rock masses with 
different lengths and analyzed the influence of fracture length on the energy indices (total energy, elastic strain energy and dissipated energy) at the peak point, as well as the length effect of the energy mutation amplitude of the fractured rock mass. Han et al. [15] conducted a uniaxial compression test on sandstone with end fractures and found that the presence of cracks reduced the energy storage degree of their samples, but that the energy consumption parameters of rocks with cracks changed only slightly. Jiang et al. [16] carried out triaxial loading test on mudstone and found that under the same confining pressure, the energy storage ratio of mudstone increased with the increase in water content, and the energy storage limit decreased linearly with the increase in water content. Meng et al. [17] studied the acoustic emission characteristics and energy evolution characteristics of rock and concluded that the internal structure of rock and axial loading stress were the main factors affecting energy storage. Xu et al. [18] conducted a cyclic loading test on cracked sandstone and found the relationship between strength and crack angle. Yin et al. [19] conducted shear tests on fractured marl and studied the mechanical properties and failure modes. Their research showed that the failure on both sides was generally tensile-shear-mixed; the tensile failure is mainly concentrated in the middle of both side. Zhang et al. [20] conducted experiments on pre-flawed sandstone to investigate the infrared radiation characteristics during failure process. They found the precursor point for pre-flawed rock failure based on the CVIRT-time curve, with an average precursor point of $83 \%$ of peak stress.

The failure of rock is the result of damage accumulation. The most basic task is selecting an appropriate damage variable to characterize the damage to the rock [21,22]. Based on the principles of residual strain [23], elastic modulus [24] and P-wave velocity [25], scholars have established expressions of damage variables. The attenuation of the elastic modulus and the accumulation of residual deformation are the external manifestations of damage; they cannot quantitatively reflect the degree of damage. Energy is the internal cause of failure, and a damage model based on the energy principle can reflect the damage evolution of the rock in the deformation-and-failure process more accurately and objectively. Wang et al. [26] established an elastic-plastic damage constitutive model and a stress-energy-rigidity-damage multi-criteria model for rock failure from the perspective of energy. Gong et al. [27] introduced a theoretical method for characterizing the damage to intact rocks under uniaxial compression conditions, providing a new means for analyzing rock damage from an energy viewpoint. Normalized dissipated energy was used to characterize the damage to the rock $[28,29]$. For fractured sandstone, a material with cracks, the initial damage must be considered, but there is no damage model to describe the damage development level and the state of fractured sandstone.

The above scholars have undertaken extensive research on the mechanical properties, crack development laws, energy evolution and damage evolution of rock masses and have achieved fruitful results. At present, there is no unified standard for the division of each stage in the process of rock deformation; most of studies have focused on intact samples, whereas few have examined the effect of the crack angle on the energy evolution and damage characteristics of fractured rock.

Thus, in this paper, the effect of crack angle is considered, and the influence of crack angle on mechanical properties and energy evolution is studied. According to the energy consumption ratio and peak point, the stages of rock deformation and failure are divided; combined with the energy dissipation theory and previous theoretical achievements, a damage model considering the initial damage in a fractured rock mass is established.

The rest of the study is structured as follows. In Section 2, the test scheme and results are introduced. In Section 3, the mechanical properties are analyzed. In Section 4, the influence of crack angle on rock energy density is discussed. In Section 5, a damage evolution model considering initial damage is established, based on the energy dissipation principle. The conclusions are given in Section 6. Figure 1 shows a schematic of the research approach. 


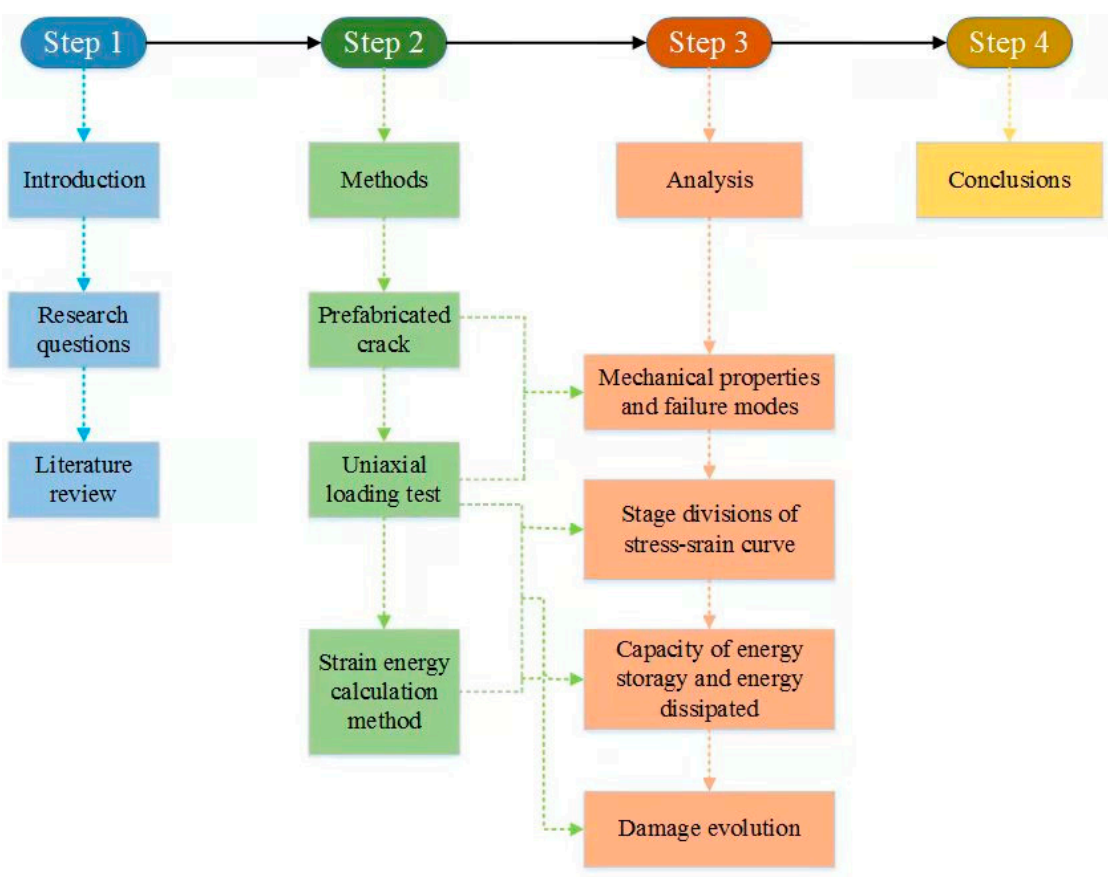

Figure 1. Schematic of the research approach.

\section{Test Scheme and Equipment}

\subsection{Test Preparation}

The sandstone specimens used in this test were taken from a mine in Huainan (Anhui, China). All specimens were from the same rock block, without obvious cracks or other defects. The sandstone was formed into a $50 \mathrm{~mm} \times 100 \mathrm{~mm}$ standard cylindrical sample using a core drilling machine and a grinding machine; the parallelism of the two end faces was greater than $98 \%$. Holes with a diameter of $2 \mathrm{~mm}$ were drilled in the middle of the specimen using a drill rig. An emery saw was passed through the drilling hole, and cut it along a prefabricated crack angle; finally, the crack angles were machined into the rock specimens. Figure 2 shows the schematic diagram of fractured sandstone. The crack angle is the included angle between the crack and the direction of principal stress. The wave velocity was measured with an MC-6310 non-metallic ultrasonic detector to eliminate the effects of anisotropy and discreteness; the wave velocity of the specimens was approximately $2.4 \mathrm{~km} / \mathrm{s}$.

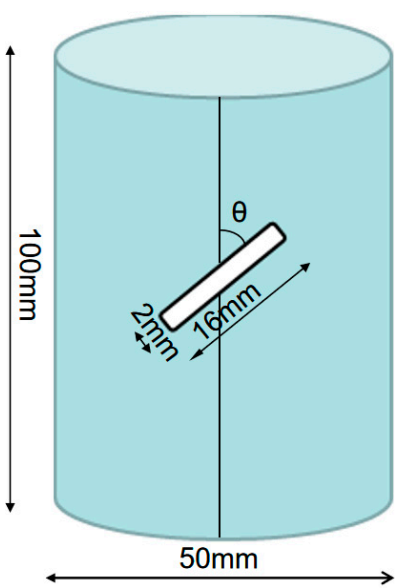

Figure 2. Schematic diagram of fractured sandstone. 


\subsection{Test Scheme and Results}

As shown in Figure 3, the RMT-150B electro-hydraulic servo-controlled test machine system, which can provide load or displacement control, was used as the load system to characterize the sandstone's mechanical behavior. Displacement load control mode was adopted in the uniaxial loading test; the loading rate was $0.01 \mathrm{~mm} / \mathrm{s}$. This experiment studied the static mechanical behavior of fractured sandstone, whose loading rate is generally $0.5-1 \mathrm{MPa}$. The peak strength of fractured sandstone is $30-50 \mathrm{MPa}$, and the peak deformation is about $0.8-1 \mathrm{~mm}$; when adopting displacement control, the rate can be taken as $0.01 \mathrm{~mm} / \mathrm{s}$.

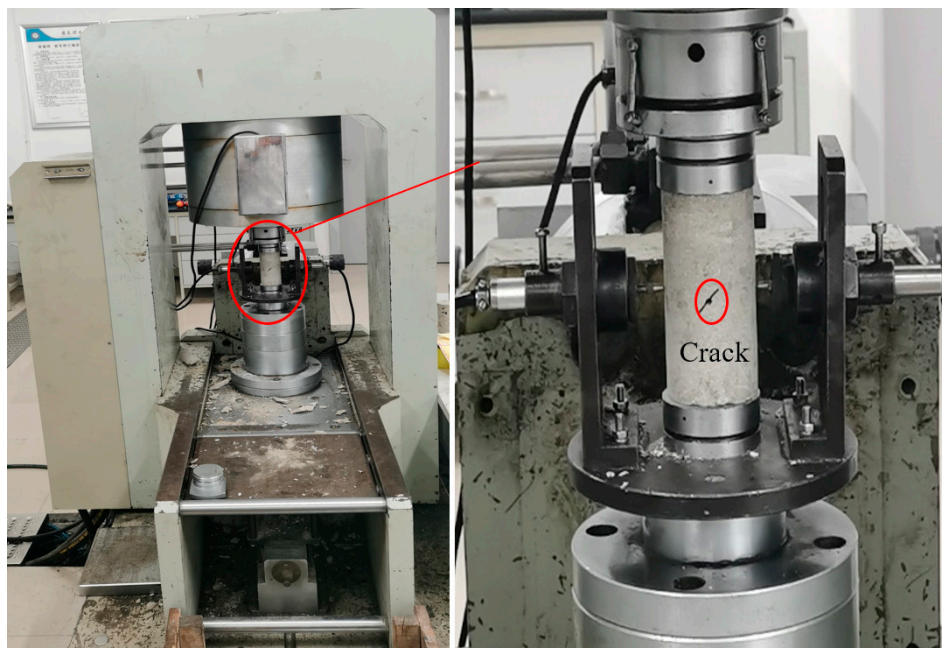

Figure 3. RMT-150B rock mechanics test system.

\section{Analysis of Mechanical Properties}

\subsection{Influence of Crack Angle on Strength and Deformation Characteristics}

The lateral and axial stress-strain curves of sandstone with different crack angles were obtained by uniaxial compression test, As shown in Figure 4, all the stress-strain curves of the specimens tested had the same pattern of variations, which can be divided into five stages. In the compaction stage, for which the stress-strain curve was concave, the deformation of rock was mainly due to the compaction and closure of microcracks. In the elastic stage, the rock mainly underwent elastic deformation, and the slope of the curve was approximately unchanged. In the yield stage, cracks parallel to the direction of principal stress were gradually connected, the slope of the curve decreases. In the failure stage, major mechanical damages continued to develop and coalesce, leading to more pronounced macroscopic failures, expressed by a rapid decrease in the bearing capacity of the specimen and a rapid increase in the specimen's deformation.

In order to compare the mechanical characteristics of sandstone with different angles more intuitively, the respective variation rules of peak strength, elastic modulus, and Poisson's ratio were plotted through Table 1. Figure 5 shows changes in the strength and its reduction ratio for rock specimens treated with different crack angles. The effect of the crack on the sandstone's deterioration is especially noticeable. With a larger crack angle, the horizontal projection area and the deterioration of the sandstone increased. The strength decreased by $17.9 \%, 24.2 \%, 27.1 \%, 35.6 \%$, and $45.4 \%$ when the crack angle was $0^{\circ}, 30^{\circ}, 45^{\circ}$, $60^{\circ}$, and $90^{\circ}$, respectively.

The elastic modulus and Poisson's ratio are two important indexes used to describe the mechanical properties of materials. There are many ways to determine the elastic modulus, including $E_{50}, E_{t}$, the slope of the approximate straight line portion of the elastic segment, and the secant modulus of the unloading curve. The evaluation method of Poisson's ratio is similar. In this study, the slope of the elastic segment of the stress-axial strain curve was 
used as the deformation modulus; the slope of the elastic segment of the lateral strain-axial strain curve was used as the Poisson ratio.



Figure 4. Stress-strain curve of fractured sandstone.

Table 1. Physical and mechanical parameters of fractured sandstone.

\begin{tabular}{|c|c|c|c|c|c|c|c|}
\hline Samples & Crack Angle/ & $\begin{array}{c}\text { Crack Length/ } \\
\text { mm }\end{array}$ & $\begin{array}{l}\text { Horizontal Projection Area/ } \\
\text { mm }^{2}\end{array}$ & $\begin{array}{c}\text { Peak Stress/ } \\
\mathrm{MPa}\end{array}$ & Peak Strain & $\begin{array}{c}\text { Elastic Modulus/ } \\
\text { GPa }\end{array}$ & Poisson's Ratio \\
\hline $\mathrm{D}-0^{\circ}$ & $0^{\circ}$ & 16 & 786.2 & 24.7 & 0.00875 & 5400 & 0.56 \\
\hline $\mathrm{D}-30^{\circ}$ & $30^{\circ}$ & 16 & 683.8 & 28.8 & 0.0088 & 6300 & 0.443 \\
\hline $\mathrm{D}-45^{\circ}$ & $45^{\circ}$ & 16 & 560.9 & 35.6 & 0.00803 & 7000 & 0.39 \\
\hline D-60 $60^{\circ}$ & $60^{\circ}$ & 16 & 398.3 & 36.9 & 0.00857 & 7200 & 0.33 \\
\hline D-90 & $90^{\circ}$ & 16 & 100.0 & 44.3 & 0.01041 & 7300 & 0.252 \\
\hline D-intact & / & 16 & 0 & 47.3 & 0.0097 & 8300 & 0.229 \\
\hline
\end{tabular}

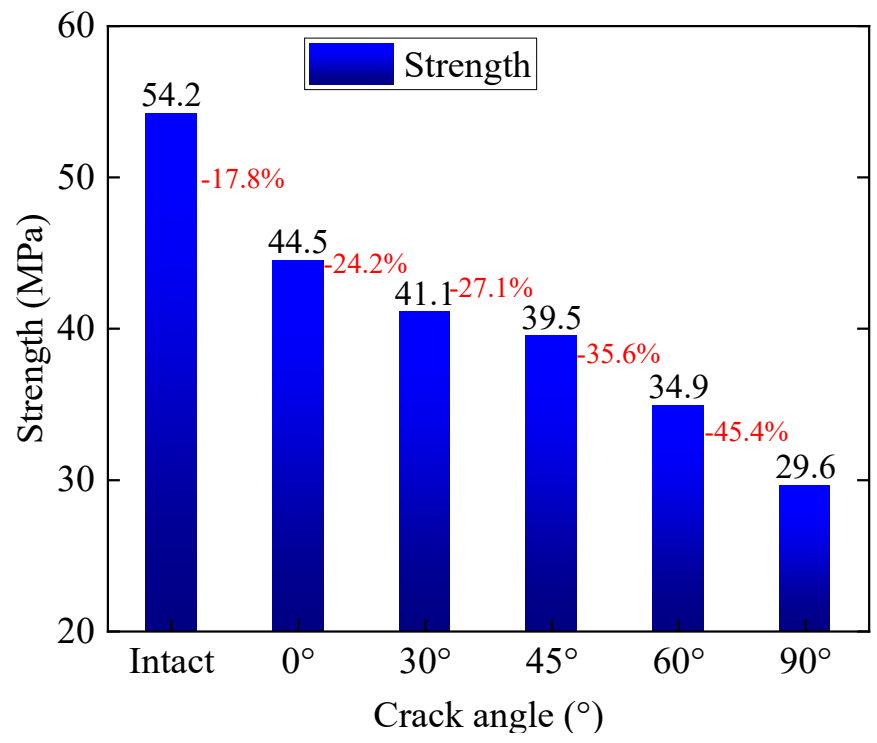

Figure 5. Strength and its reduction ratio for sandstone with different crack angles.

As can be seen in Figure 6, the effect of the crack on the elastic modulus was noticeable. With an increase in crack angle, the elastic modulus decreased steadily. Compared to the complete specimen, the elastic modulus decreased by $10.8 \%, 13.3 \%, 16.9 \%, 24.1 \%$, and $34.9 \%$ when the crack angle was $0^{\circ}, 30^{\circ}, 45^{\circ}, 60^{\circ}$, and $90^{\circ}$, respectively. 


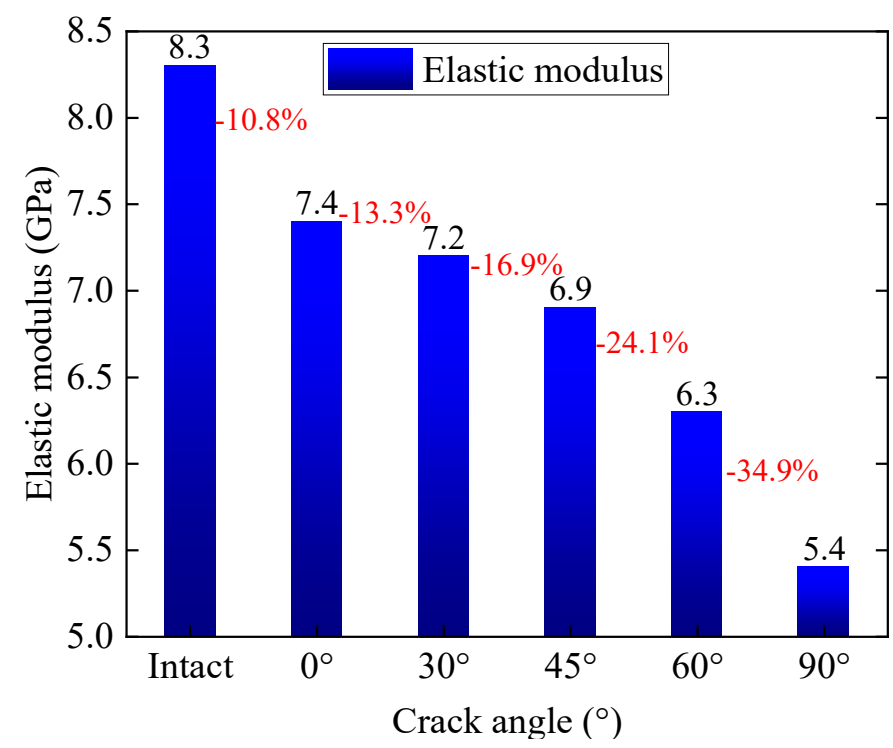

Figure 6. Elastic modulus and its reduction ratio for rock specimens with different crack angles.

As can be seen in Figure 7, with an increase in crack angle, the Poisson's ratio increased steadily. Compared to the complete specimen, the Poisson's ratio increases by $9.9 \%, 33.2 \%$, $38.4 \%, 51.7 \%$, and $70.7 \%$ when the crack angle was $0^{\circ}, 30^{\circ}, 45^{\circ}, 60^{\circ}$, and $90^{\circ}$, respectively.



Figure 7. Poisson's ratio and its increase ratio for rock specimens with different crack angles.

The deterioration effect of prefabricated cracks on the rocks was reflected in fact that in the projected area of cracks, the larger the crack angle, the smaller the ability to resist deformation, and the larger the degradation of the mechanical properties. Hence, with the increase in crack angle, the strength and elastic modulus increase and the Poisson's ratio decrease were consistent with the research results of Peng et al. [30]. This paper quantitatively describes the degree of reduction.

\subsection{Failure Mode}

Figure 8 shows the failure modes of five prefabricated fractured sandstones and one complete sandstone. The failure mode of the sandstone was brittle failure, and almost all the specimens had penetrating oblique fracture surfaces. The intact sandstone specimen had a penetrating fracture and a fracture that did not extend to the bottom; the failure 
mode was between single inclined plane shear failure and conjugate shear failure. The failure surface of the D- $0^{\circ}$ specimen was collinear with the prefabricated crack, which was a tensile failure. The angles of the prefabricated fracture were perpendicular to the Poisson effect, which weakened the stones' ability to resist the Poisson effect. The D- $30^{\circ}, \mathrm{D}-45^{\circ}$, and $\mathrm{D}-60^{\circ}$ specimens showed a single inclined shear failure mode. The prefabricated D-90 fractured sandstone specimen had a penetrating fracture and several second cracks; the failure mode was single inclined plane shear failure.

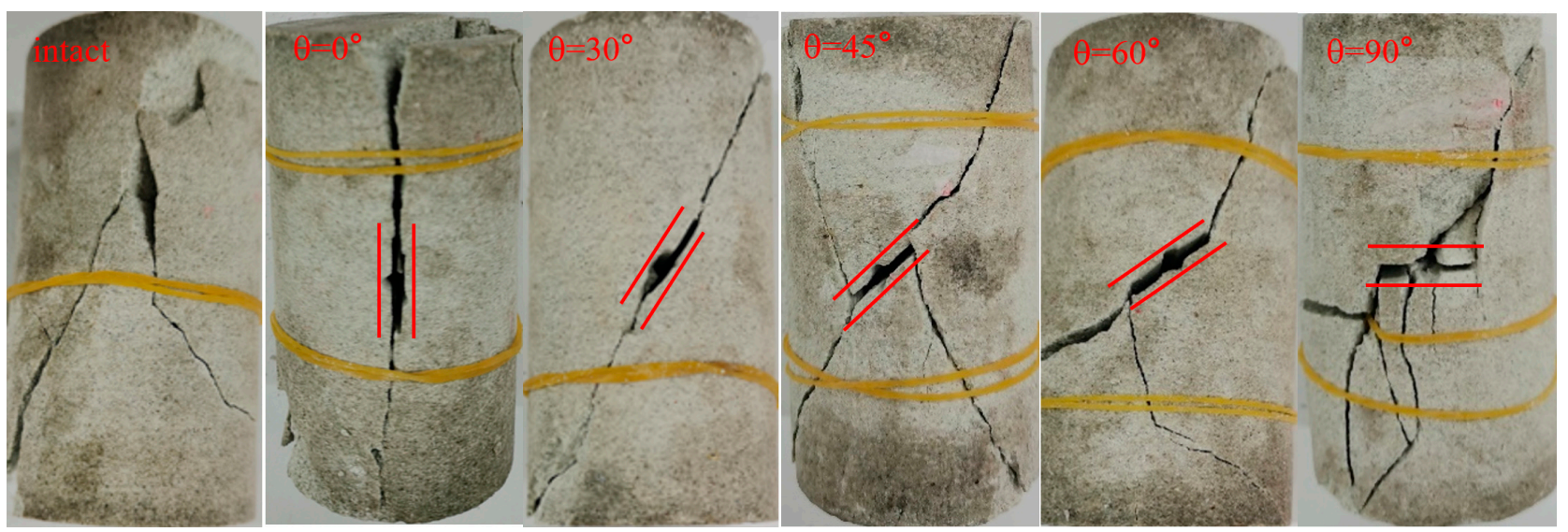

Figure 8. Failure modes of fractured sandstone.

The crack extended from the two ends of the prefabricated crack to the end surface and gradually developed into the main crack to form the fracture surface. The $\mathrm{D}-0^{\circ}$, D-30 $0^{\circ}$, and D $-45^{\circ}$ specimens all showed cracks that were approximately collinear with the prefabricated crack, which obviously accelerated the coalescence of the cracks. The prefabricated cracks of the $\mathrm{D}-60^{\circ}$ and $\mathrm{D}-90^{\circ}$ specimens formed certain angles with the penetrating fracture surface that were not along the direction of the prefabricated cracks, which indicated that the prefabricated cracks had more of an influence on the crack's initiation position; the crack angle had only a slight effect on the failure mode; with the exception of the $\mathrm{D}-0^{\circ}$ specimen, the failure modes of the specimens were all shear failure.

Rock always breaks along the weak surface. Under the action of load, cracks gradually sprout, expand, and finally connect into the failure surface. The presence of prefabricated cracks changes the distribution of weak surface and speeds up the formation of fracture surface [31,32]. When the fracture angle is collinear with the oblique shear failure surface or the included angle is small, the prefabricated fracture mainly accelerates the formation of the fracture surface, and there are few branch fractures. When the angle between the prefabricated crack and the inclined failure surface is large, the prefabricated crack surface not only connects the failure surface and speeds up the formation of the failure surface, but also has weak points away from the failure surface. On the whole, there are more potential crack initiation points, and then more branch cracks are formed.

\section{Analysis of Energy Evolution of Fractured Sandstone}

\subsection{Energy Conversion Theory under Cyclic Loading}

Rock failure is essentially an energy-driven instability phenomenon. Therefore, the deformation and failure rule of fractured sandstone can be investigated using energy theory, which is helpful for characterizing the mechanical behavior of sandstones with different cracks. Generally speaking, the energy evolution of a rock under loading can be divided into four processes: energy input, accumulation, dissipation, and release. The input energy mainly comes from the work performed by the external force; the elastic energy is stored in the rock in the form of elastic deformation; and the dissipated energy, including the plastic energy and fracture surface energy, is employed to induce damage and results in strength degradation. It was assumed that there was no heat exchange in the process of rock 
deformation and failure, and acoustic emission energy and radiant energy were ignored. According to the first law of thermodynamics, the work performed by the external force is the total input energy and the relationship of input energy, elastic energy, and dissipated energy, which can be expressed as

$$
U=U_{e}+U_{d}
$$

where $U, U_{e}, U_{d}$ represent input energy, elastic energy, and dissipated energy, respectively. The correlation is shown in Figure $9[33,34]$. The area $U_{d}$ represents the consumed energy of the element during damage and plastic deformation. The shaded area $U_{e}$ represents the releasable strain energy stored in the element and corresponds to the elastic strain energy released by the rock element after unloading. $E$ is the elastic modulus.

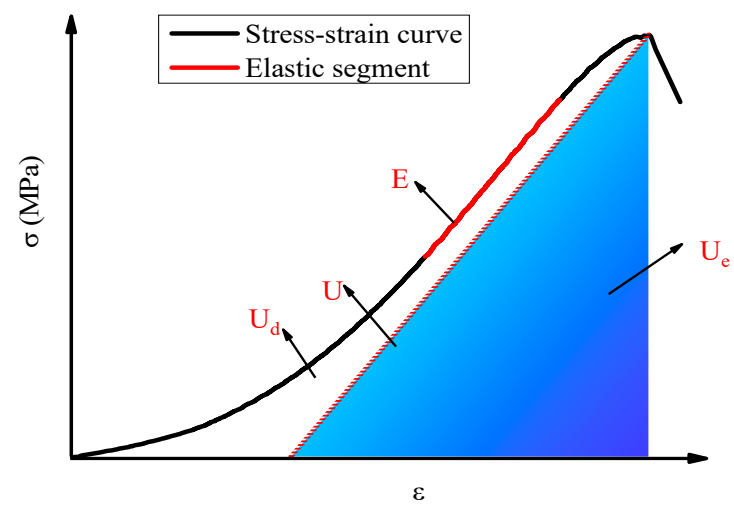

Figure 9. Diagram for the calculation of energy.

In the case of three-dimensional stress, according to the method suggested by Yang [35] and Cheng [36], the energy in the principal stress space can be expressed as follows:

$$
\begin{gathered}
U=\int_{0}^{\varepsilon_{i}} \sigma_{i} d \varepsilon_{i} \\
U_{e}=\frac{1}{2} \sigma_{i} \varepsilon_{e i}
\end{gathered}
$$

Assuming that the stress-strain relationship of rock obeys the generalized Hooke's law,

$$
\varepsilon_{e i}=\frac{1}{E}\left(\sigma_{i}-\mu\left(\sigma_{j}+\sigma_{k}\right)\right)
$$

Substitute Equation (4) into Equation (3) to obtain the expression of elastic energy,

$$
U_{e}=\frac{1}{2 E}\left(\sigma_{i}^{2}-2 \mu \sigma_{i} \varepsilon_{j}\right)
$$

where $\sigma_{i}(i=1,2,3)$ is the principal stress in all directions; $\varepsilon_{i}, \varepsilon_{e i}$ are the strain and elastic strain in the direction of principal stress, respectively; and $E$ is the elastic modulus.

\subsection{Energy Evolution Laws and Stage Divisions of Fractured Sandstone}

The evolution laws of the input energy, elastic energy, and dissipated energy were obtained using Equations (1)-(5). Figure 10 shows the stress-strain curve and the evolution curves of the sandstones with different angles. The stress-strain curves and energy index curves of the fractured sandstone with different angles exhibit similar rules. The input energy increased monotonically throughout the deformation and failure process; the elastic energy gradually accumulated before the peak and rapidly released after the peak, and the trend is similar to the stress-strain curve; the curve of dissipated energy showed a trend of slow-steady-sharp growth throughout the whole deformation and failure process. 


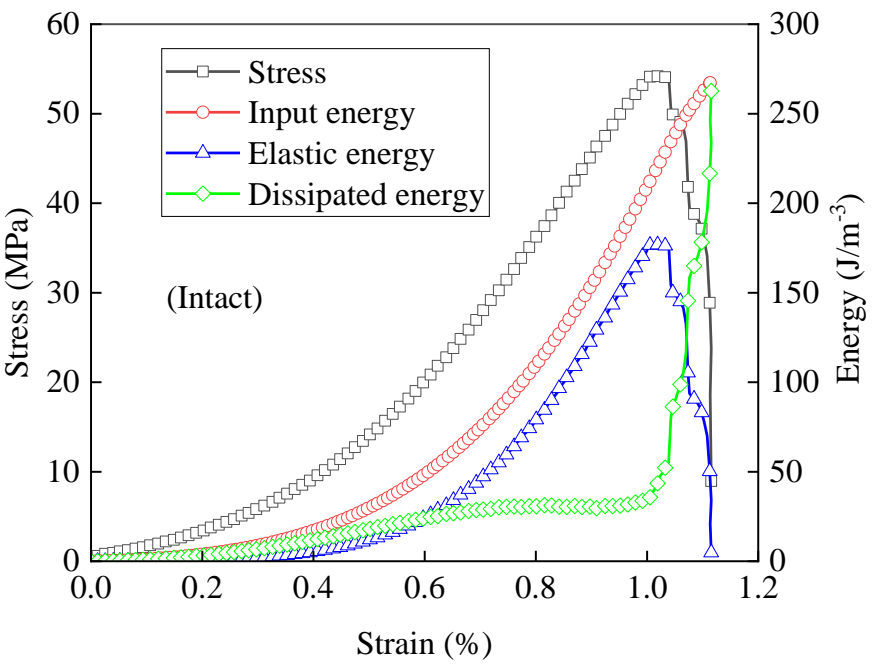

(a)



(c)

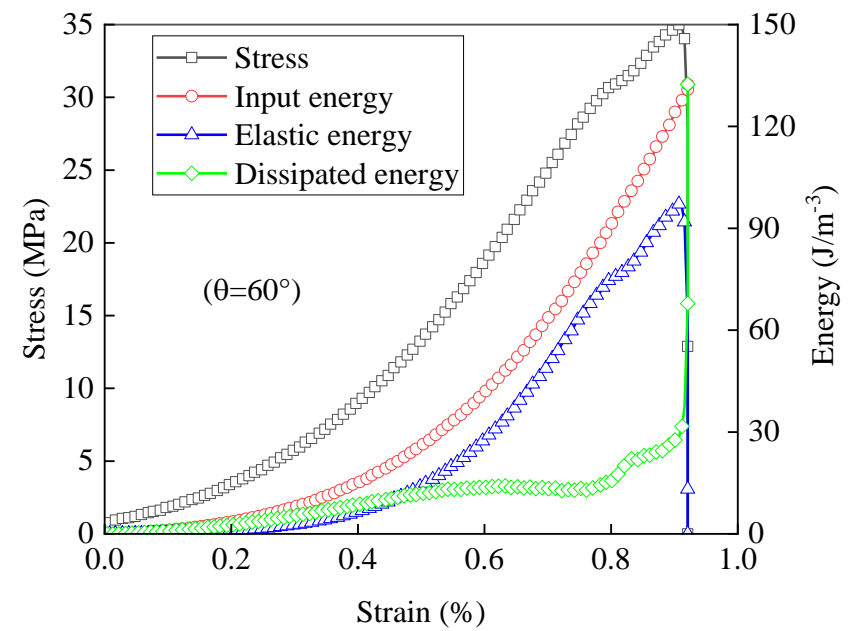

(e)



(b)

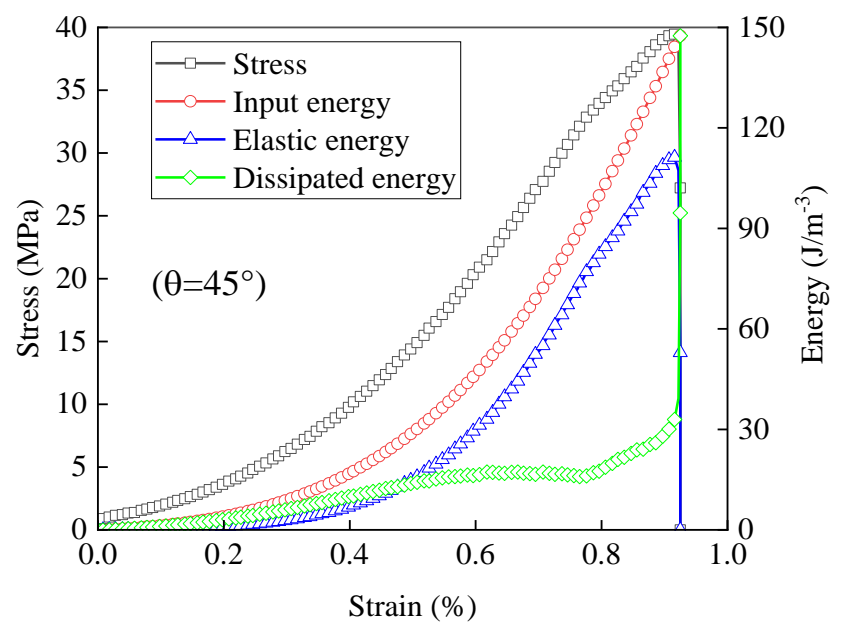

(d)

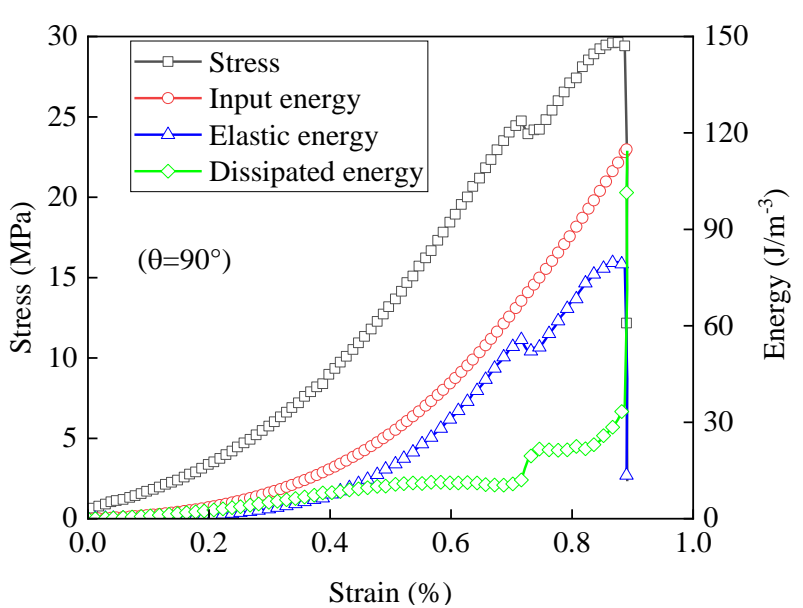

(f)

Figure 10. Energy evolution curve of fractured sandstone. (a) intact, (b) $\theta=0^{\circ}$, (c) $\theta=30^{\circ}$, (d) $\theta=45^{\circ}$, (e) $\theta=60^{\circ}$, (f) $\theta=90^{\circ}$. 
The energy evolution of rock is mainly a transformation among input energy, elastic energy, and dissipated energy; the energy consumption ratio is defined as the proportion of dissipated energy to input energy, and the energy storage ratio is defined as the proportion of elastic energy to input energy. The curves of the energy consumption ratio and energy storage ratio reflect the dynamic transformation process of energy. To compare the transformation relationship between the three more clearly and intuitively, and to divide each stage of the stress-strain curve, the intersection of the curves of the energy consumption ratio and the energy storage ratio was regarded as the dividing point between the compaction stage and the elastic stage. The highest point of the energy storage ratio curve (the lowest point of the energy consumption ratio curve) served as the dividing point between the elastic stage and the yield stage. The peak point was used as the dividing point between the yield stage and the failure stage. The stress-strain curve was divided into the compaction stage, the elastic stage, the yield stage, and the failure stage. The boundary points of each stage were the compaction point, yield point, and peak point.

In the compaction stage, the deformation of rock was mainly due to the compaction and closure of microcracks. Most of the energy input in this stage was converted into dissipated energy, so the energy consumption ratio was always greater than the energy storage ratio. However, with the gradual closure of the cracks and pores, the elastic deformation capacity increased, the energy consumption ratio decreased, and the energy storage ratio increased.

In the elastic stage, the growth rate of the dissipated energy decreased gradually; the stored elastic energy began to exceed the dissipated energy and gradually increased to its maximum. The energy storage ratio gradually increased and the energy consumption ratio gradually decreased. The rock mainly underwent elastic deformation and most energy was stored in the form of elastic energy.

In the yield stage, the elastic energy was stored continuously, but the growth rate slowed down; before reaching the energy storage limit, the speed of the dissipated energy increased, the energy consumption ratio increased, and the energy storage ratio decreased, because the energy dissipated by the crack propagation and penetration increased.

In the failure stage, the sandstone sample continuously absorbed energy, the dissipated energy accumulates rapidly, the elastic energy was used as the driving force behind the formation of the rock fracture surface, the bearing capacity was rapidly lost, and the rock was destroyed.

The crack angle had only a slight influence on the compaction stage and elastic stage, but it had a significant influence on the yield stage and the failure stage, as can be seen in Figure 11. With the increase in the crack angle, the yield stage became shorter and the destruction stage became longer.

\subsection{Influence of Crack Angle on Energy at Peak Point}

The energy evolution of rock is mainly a transformation among input energy, elastic energy and dissipated energy. To compare the transformation relationship between the three more clearly and intuitively, the energy consumption ratio was defined as the proportion of dissipated energy to input energy, and the energy storage ratio was defined as the proportion of elastic energy to input energy. The curves of the energy consumption ratio and energy storage ratio reflect the dynamic transformation process of energy.

At the peak point, the elastic strain energy of the rock sample reached the limit value of energy storage and then released. Part of the elastic strain energy was converted into dissipated energy, and part of it dissipated in the form of kinetic energy and radiation energy. The dissipated energy increased sharply after the peak point. In order to further analyze the variations in the energy storage capacity and energy consumption capacity of rock samples with fracture angles, the energy indexes of the peak points of the rock samples are plotted in Figures 12 and 13. 


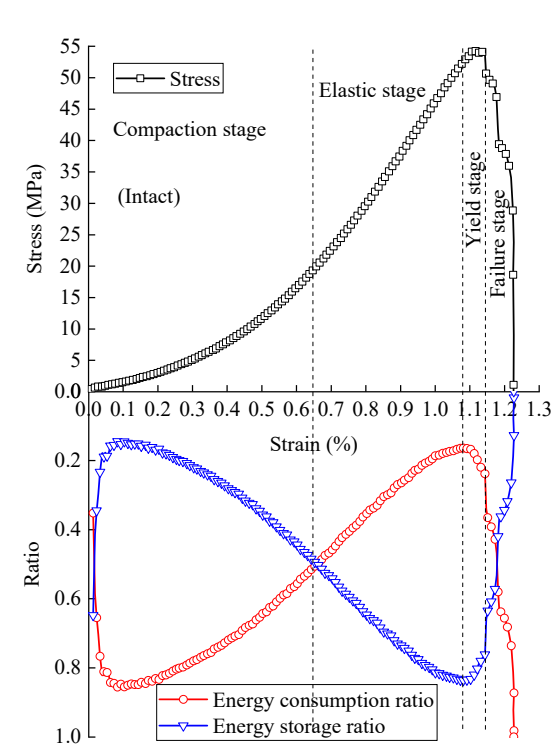

(a)



(d)

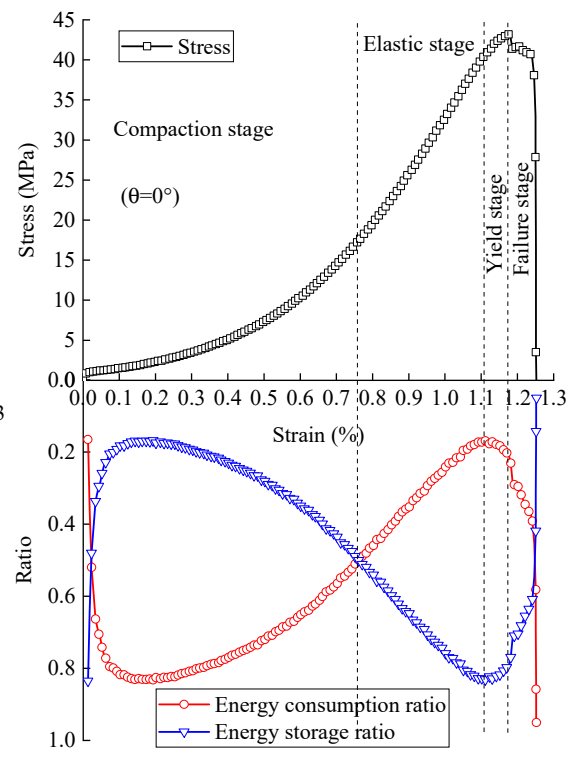

(b)

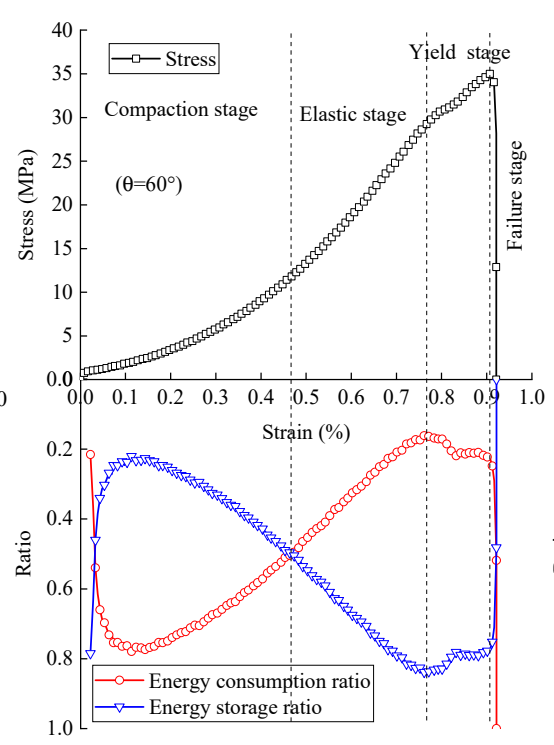

(e)

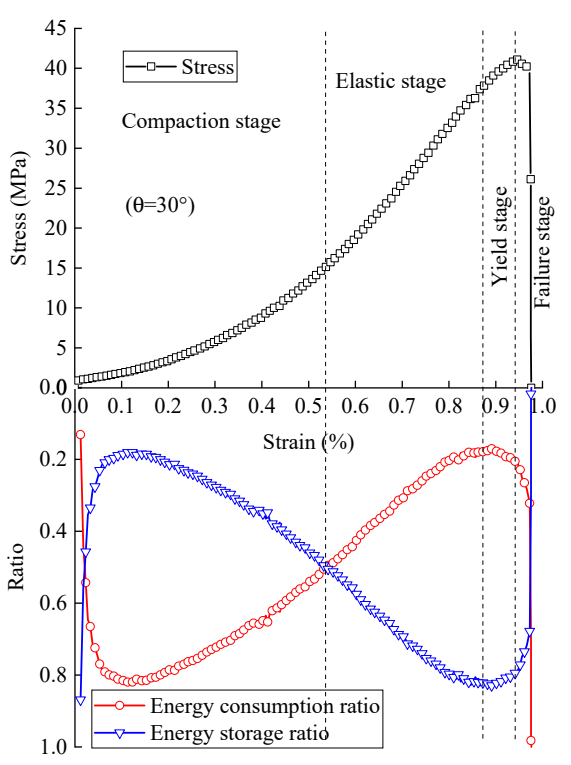

(c)



(f)

Figure 11. Stage division and curves of the energy storage ratio and energy consumption ratio. (a) intact, (b) $\theta=0^{\circ}$, (c) $\theta=30^{\circ}$, (d) $\theta=45^{\circ}$, (e) $\theta=60^{\circ}$, (f) $\theta=90^{\circ}$.

Figure 12 shows the evolution curves of the input energy, elastic energy, and dissipated energy of the fractured sandstone with different angles at the peak point. The elastic energy, dissipated energy, and input energy of the fractured rock samples at the peak point always decreased with an increase in crack angle. This is because the smaller the crack angle, the larger the horizontal projection area of the fracture, and the larger the initial damage. The decreases in the input energy and elastic energy were large, whereas the decrease in the dissipation energy was small.

As shown in Figure 13, the energy storage ratios of the fractured sandstone with different crack angles were 80.2\%, 79.2\%, 78.9\%, 78.3\%,77.3\%, and $73 \%$, and the energy consumption ratios were $19.8 \%, 20.8 \%, 21.1 \%, 21.7 \%, 22.7 \%$, and $27 \%$, respectively. The energy storage ratio was much higher than the energy consumption ratio. The energy storage ratio at the peak point decreased with an increase in crack angle, and the energy 
consumption ratio increased with a decrease in crack angle, indicating that with increases in crack angle, the initial damage caused by the crack increased gradually, and that the crack angle enhanced the energy dissipation capacity and reduced the energy storage capacity ratio at the peak point.

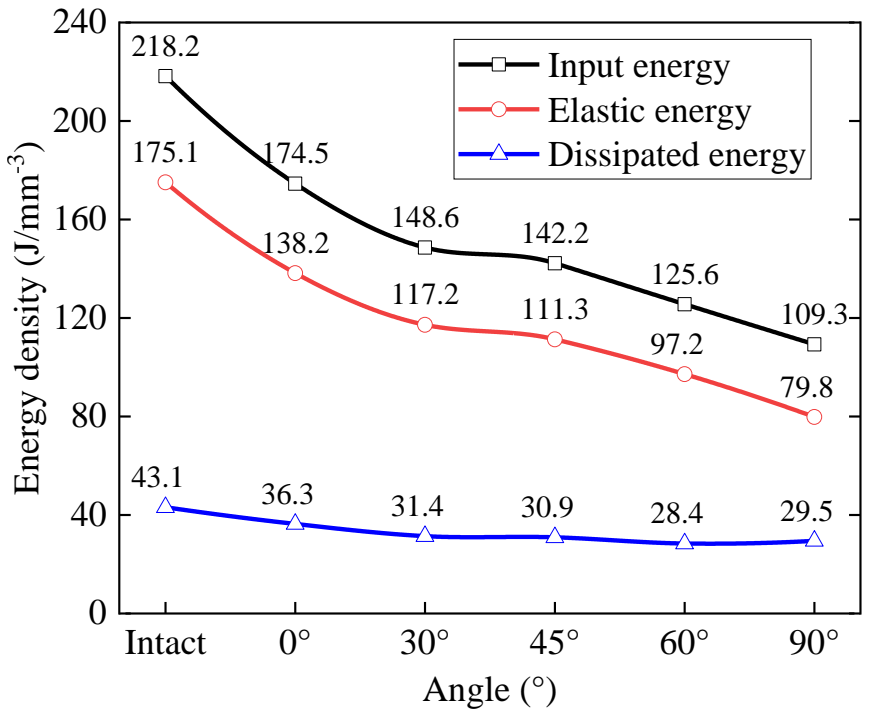

Figure 12. Energy density at the peak point.



Figure 13. Energy storage ratio and energy consumption ratio.

The effect of the crack weakened the supporting capacity of the rock skeleton, which led to the degradation of the sandstone's strength, a decrease in the crack toughness, and stress concentration near the defects, making it easy to generate new cracks near the crack, and exhibiting an increase in dissipated energy.

\section{Damage Mechanism Based on Energy Dissipation}

\subsection{Damage Model Based on Energy Dissipation Theory and Initial Damage}

Rock failure belongs to an unstable phenomenon driven by energy, and the dissipated energy helps to cause rock failure. Internal damage to rock samples in the process of deformation inevitably leads to the accumulation of elastic strain energy in the rock sample, which is released in the form of dissipated energy; each stage of rock deformation and failure is related to dissipated energy. Thus, it is more reasonable to use normalized 
dissipated energy to represent damage variables. The damage variable calculated in Equation (6) is between 0 and 1, and it satisfies the irreversible principle.

The damage variable is defined as

$$
D=\frac{\sum U_{\mathrm{d}}}{U_{\mathrm{d}}}
$$

The sandstone used in this test was relatively dense, without obvious cracks or other defects. Compared with the prefabricated cracks, the natural primary cracks could be ignored; thus, it was assumed that there was no initial damage to the rock before prefabrication. There are obvious fracture surfaces in the fractured sandstone, and the mechanical properties (such as strength, elastic modulus and Poisson's ratio) of the fractured sandstone samples were quite different from those of the intact sandstone, so the influence of initial damage had to be considered. For the initial damage to the fractured sandstone, it was supposed that the crack had not expanded, and the initial damage was related to the effective bearing area [37]. The damage defined by the effective bearing area of the sandstone is

$$
D_{0}=\frac{S_{f}}{S}
$$

where $S_{f}$ is the projected area of the fracture surface in the horizontal direction, $S$ is the projected area of the specimen in the horizontal direction, and the horizontal projected area + effective bearing area $=$ horizontal projected area of sample.

Thus, the damage model, considering the initial damage of the fractured sandstone, is

$$
D=D_{0}+\frac{\sum U_{\mathrm{ds} i}}{U_{\mathrm{ds}}}\left(1-D_{0}\right)
$$

where $D_{0}$ is initial damage, $\sum U_{\mathrm{d}}$ is the cumulative dissipated energy, and $U_{\mathrm{d}}$ is the total dissipated energy.

\subsection{Damage Evolution and Energy Damage Mechanism}

To observe the damage evolution of sandstone with different crack angles and to grasp the overall laws underlying the process, the strain and stress were normalized, respectively. In accordance with Equation (8), the damage-normalized strain curve and the damagenormalized stress curve were obtained. As shown in Figure 14, the smaller the crack angle, the higher the initial position of the curve, because the smaller the crack angle, the smaller the effective bearing area and the larger the initial damage. The damage variable showed a trend of slow accumulation-steady accumulation-rapid accumulation. There was a mutation point between the steady accumulation stage and the sharp accumulation stage, which corresponded to the yield point on the stress-strain curve. With an increase in crack angle, the yield point was close to the failure point. The yield stage was not obvious, and the failure occurred suddenly. The analysis showed that the failure of rock was caused by crack initiation, propagation, and penetration, and finally the formation of the fracture surface. For the fractured sandstone, the stiffness deteriorated and the fracture surface formed locally, accelerating the formation of the fracture surface, so the failure occurred suddenly. The initial damage caused by cracks is considered in this paper, and the evolution law of damage variables is consistent with previous studies [38,39].

As shown in Figure 15, the damage-normalized stress curve is similar to a parabola, with an opening to the left. Before the peak stress, the damage curve increases with an increase in stress. After the peak stress, although the stress decreased, the damage accumulated rapidly. This is because in the failure stage, although the crack propagation reduced the bearing capacity, the deformation of the specimen increased, external force was still exerted on the specimen, and, at this time, the elastic energy reached the energy storage limit. Most of the input energy was converted into dissipated energy, and even 
part of the elastic energy was released and converted into dissipated energy, causing the fracture of the specimen.

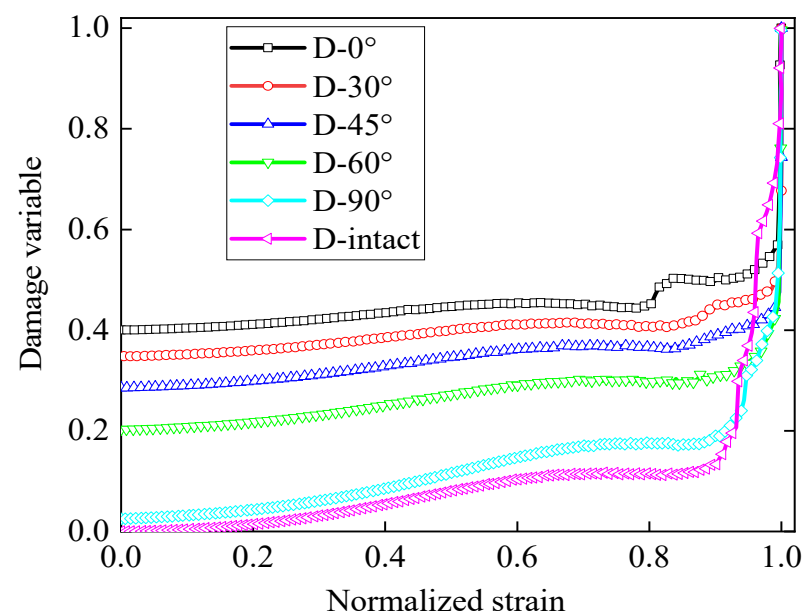

Figure 14. Damage variable-normalized strain curve.

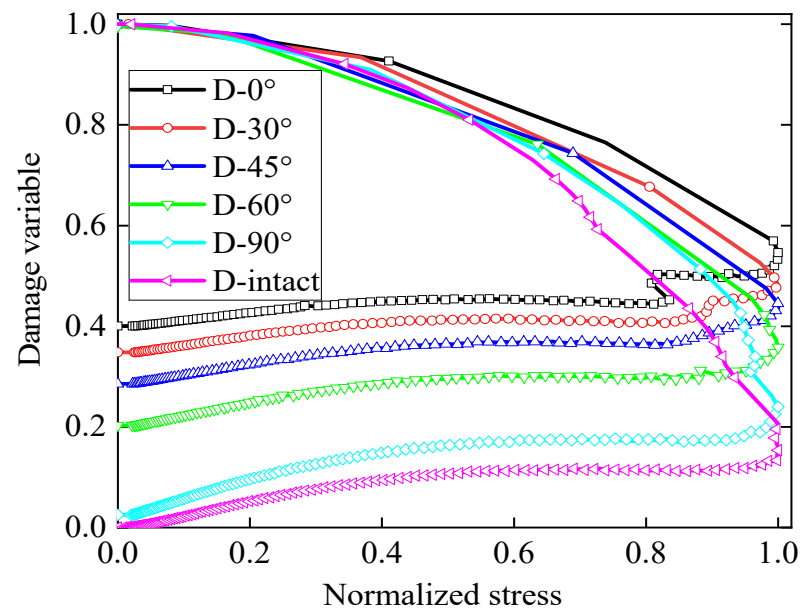

Figure 15. Damage variable-normalized stress curve.

Dissipated energy is the essential attribute of rock compression failure and provides the positive work to cause rock failure, which reflects the development of microcracks in sandstone. The strength gradually weakening the stored elastic energy is the dynamic source of rock failure. The mutual transformation and transfer of the two eventually led to the failure of the fractured sandstone in this study.

The damage variable is mainly characterized by dissipated energy and the projected area of the crack. The crack angle (crack area) affected the initial damage to the specimen, and the dissipated energy affected the variation trend of the damage variable. The damage evolution curve was similar to the evolution curve of the dissipated energy. The proportion of damage accumulated before the yield stage was very small, and most of the damage accumulated after the yield stage. For each specimen, the cumulative damage before the yield stage did not exceed $20 \%$. This indicates that crack initiation was slow and that less energy was dissipated before the yield stage. When the yield stage was reached, the crack rapidly penetrated into the fracture surface and dissipated a large amount of energy, which indirectly indicated the brittleness and sudden failure of the rock.

\section{Conclusions}

(1) The strength and elastic modulus of sandstone decrease with an increase in crack angle, and Poisson's ratio increases with an increase in crack angle. The smaller the 
crack angle, the closer the mechanical properties are to those of the complete specimen. Prefabricated cracks affect the crack initiation position of the fracture surface and accelerate the formation of the fracture surface.

(2) In this study, the stress-strain curve was divided into compaction stage, elastic stage, yield stage, and failure stage. The crack angle had a great influence on the yield stage and the failure stage. The larger the crack angle, the longer the yield stage and the shorter the failure stage.

(3) The elastic energy, dissipated energy, and input energy of fractured sandstone at the peak point always decrease with an increase in the crack angle. The energy consumption ratio increases with an increase in the crack angle, and the energy storage ratio decreases with an increase in the crack angle.

(4) Based on the energy dissipation principle, a damage model considering the initial damage to fractured sandstone was established. The damage variable shows a trend of slow accumulation-steady accumulation-rapid accumulation. The crack angle (crack area) affects the initial damage to the specimen, and the dissipated energy affects the variation trend of the damage variable.

Author Contributions: Conceptualization, Z.Y. and X.L. (Xinwei Li); methodology, X.L. (Xinwei Li); investigation, X.H.; data curation, X.L. (Xiaohu Liu); writing-original draft preparation, X.L. (Xinwei Li); writing-review and editing, X.L. (Xiaohu Liu); project administration, Z.Y.; funding acquisition, Z.Y. All authors have read and agreed to the published version of the manuscript.

Funding: This research was funded by the graduate research project of the Anhui Provincial Department of Education of China (YJS20210382); the National Natural Science Foundation of China (51674006), the Anhui Provincial College of Natural Science Research Key Project (KJ2018A0098), and the China Postdoctoral Science Foundation (2018M642502).

Institutional Review Board Statement: Not applicable.

Informed Consent Statement: Not applicable.

Data Availability Statement: Not applicable.

Conflicts of Interest: The authors declare no conflict of interest.

\section{References}

1. Gao, Y.H.; Feng, X.T. Study on damage evolution of intact and jointed marble subjected to cyclic true triaxial loading. Eng. Fract. Mech. 2019, 215, 224-234. [CrossRef]

2. Akdag, S.; Karakus, M.; Nguyen, G.D.; Taheri, A. Strain burst vulnerability criterion based on energy-release rate. Eng. Fract. Mech. 2020, 237, 107232. [CrossRef]

3. Bi, X.F.; Wang, W.C.; Zhu, G.F.; Liu, X.L. Study of mechanical behavior of salt rock with prefabricated fissures under different confining pressures. Arab. J. Geosci. 2021, 14, 785. [CrossRef]

4. Wang, Y.; Han, J.Q.; Li, C.H. Acoustic emission and CT investigation on fracture evolution of granite containing two flaws subjected to freeze-thaw and cyclic uniaxial increasing-amplitude loading conditions. Constr. Build. Mater. 2020, $260,119769$. [CrossRef]

5. Huang, X.W.; Yao, Z.S.; Cai, H.B.; Li, X.W.; Chen, H.Q. Performance evaluation of coaxial borehole heat exchangers considering ground non-uniformity based on analytical solutions. Int. J. Therm. Sci. 2021, 170, 107162. [CrossRef]

6. Yin, L.; Li, M.; Sun, W.B.; Chen, J.T.; Liu, B.; Wang, Z.Q. Mechanical mechanism and propagation law of fissure-tip cracks of large-size rock specimens with two precut fissure. Shock Vib. 2021, 2021, 8812902. [CrossRef]

7. Gratchev, L.; Kim, D.H.; Yeung, C.K. Strength of rock-like specimens with pre-existing cracks of different length and width. Rock Mech. Rock Eng. 2016, 49, 4491-4496. [CrossRef]

8. Xu, L.; Gong, F.Q.; Luo, S. Effects of pre-existing single crack angle on mechanical behaviors and energy storage characteristics of red sandstone under uniaxial compression. Theor. Appl. Fract. Mec. 2021, 113, 102933. [CrossRef]

9. Zhong, Z.B.; Deng, R.G.; Zhang, J.; Hu, X.Z. Fracture properties of jointed rock infilled with mortar under uniaxial compression. Eng. Fract. Mech. 2020, 228, 106822. [CrossRef]

10. Deng, Y.; Chen, M.; Jin, Y.; Zou, D.W. Theoretical analysis and experimental research on the energy dissipation of rock crushing based on fractal theory. J. Nat. Gas Sci. Eng. 2016, 33, 231-239. [CrossRef]

11. Zhao, Y.C.; Yang, T.H.; Xu, T.; Zhang, P.H.; Shi, W.H. Mechanical and energy release characteristics of different water-bearing sandstones under uniaxial compression. Int. J. Damage Mech. 2018, 27, 640-656. [CrossRef] 
12. Gao, D.Y.; Sang, S.X.; Liu, S.Q.; Geng, J.S.; Wang, T.; Sun, T.M. Investigation of the Energy Evolution of Tectonic Coal under Triaxial Cyclic Loading with Different Loading Rates and the Underlying Mechanism. Energies 2021, 14, 8124. [CrossRef]

13. Li, K.Q.; Li, D.Q.; Liu, Y. Meso-scale investigations on the effective thermal conductivity of multi-phase materials using the finite element method. Int. J. Heat Mass Tran. 2020, 151, 119383. [CrossRef]

14. Zhang, L.; Wang, G.L.; Lei, R.D.; Wen, X.X.; Liu, B.L.; Sun, F. Study on the energy damage evolution mechanism of single jointed rock mass with different length under uniaxial compression. China J. Highw. Transt. 2021, 34, 24-34. (In Chinese)

15. Han, Z.Y.; LI, D.Y.; Zhu, Q.Q.; Liu, M.; Li, X.B. Uniaxial compression failure and energy dissipation of marble specimens with flaws at the end surface. Adv. Eng. Sci. 2020, 42, 1588-1596. (In Chinese)

16. Jiang, J.D.; $\mathrm{Xu}, \mathrm{J}$. Investigation of energy mechanism and acoustic emission characteristics of mudstone with different moisture contents. Shock Vib. 2018, 2018, 2129639. [CrossRef]

17. Meng, Q.B.; Zhang, M.W.; Han, L.J.; Pu, H.; Nie, T.Y. Effects of acoustic emission and energy evolution of rock specimens under the uniaxial cyclic loading and unloading compression. Rock Mech. Rock Eng. 2016, 49, 3873-3886. [CrossRef]

18. Xu, Y.; Ren, F.Y.; Ahmed, Z.K.; Wang, K.Y.; Wang, Z.H. Mechanical characteristics and damage evolution law of sandstone with prefabricated cracks under cyclic loading. Arab. J. Sci. Eng. 2021, 46, 10641-10653. [CrossRef]

19. Yin, Z.M.; Liu, X.R.; Yang, Z.P.; Wang, Y.L. Shear behavior of marlstone containing parallel fissure under normal unloading. KSCE J. Civ. Eng. 2021, 25, 1283-1294. [CrossRef]

20. Zhang, K.; Liu, X.H.; Chen, Y.L.; Cheng, H.M. Quantitative description of infrared radiation characteristics of preflawed sandstone during fracturing process. J. Rock Mech. Geotech. 2021, 13, 131-142. [CrossRef]

21. Peng, R.; Ju, Y.; Wang, J.G.; Xie, H.; Gao, F.; Mao, L. Energy dissipation and release during coal failure under conventional triaxial compression. Rock Mech. Rock Eng. 2015, 48, 509-526. [CrossRef]

22. Jiang, C.; Duan, M.; Yin, G.; Wang, J.G.; Lu, T.; Xu, J.; Zhang, D.; Huang, G. Experimental study on seepage properties, AE characteristics and energy dissipation of coal under tiered cyclic loading. Eng. Geol. 2017, 221, 114-123. [CrossRef]

23. Zhao, H.; Shi, C.J.; Zhao, M.H.; Li, X.B. Statistical damage constitutive model for rocks considering residual strength. Int. J. Geomech. 2017, 17, 04016033. [CrossRef]

24. Yang, S.; Zhang, N.; Feng, X.W.; Kan, J.G.; Pan, D.J.; Qian, D.Y.; Reccia, E. Experimental investigation of sandstone under cyclic loading: Damage assessment using ultrasonic wave velocities and changes in elastic modulus. Shock Vib. 2018, 2018, 7845143. [CrossRef]

25. Zhao, G.J.; Chen, C.; Yan, H.; Hao, Y.L. Study on the damage characteristics and damage model of organic rock oil shale under the temperature effect. Arab. J. Geosci. 2021, 14, 722. [CrossRef]

26. Wang, C.L.; He, B.B.; Hou, X.L.; Li, J.Y.; Liu, L. Stress-energy mechanism for rock failure evolution based on damage mechanics in hard rock. Rock Mech. Rock Eng. 2020, 53, 1021-1037. [CrossRef]

27. Gong, F.Q.; Zhang, P.L.; Luo, S.; Li, J.C.; Huang, D. Theoretical damage characterisation and damage evolution process of intact rocks based on linear energy dissipation law under uniaxial compression. Int. J. Rock Mech. Min. 2021, 146, 104858. [CrossRef]

28. Liu, Y.; Dai, F.; Dong, L.; Xu, N.W.; Feng, P. Experimental investigation on the fatigue mechanical properties of intermittently jointed rock models under cyclic uniaxial compression with different loading parameters. Rock Mech. Rock Eng. 2018, 51, 47-68. [CrossRef]

29. Cheng, C.; Li, X. Cyclic experimental studies on damage evolution behaviors of shale dependent on structural orientations and confining pressures. Energies 2018, 11, 160. [CrossRef]

30. Peng, K.; Wang, Y.Q.; Zou, Q.L.; Liu, Z.P.; Mou, J.H. Effect of crack angles on energy characteristics of sandstones under a complex stress path. Eng. Fract. Mech. 2019, 218, 106577. [CrossRef]

31. Yin, Q.; Jing, H.W.; Su, H.J. Investigation on mechanical behavior and crack coalescence of sandstone specimens containing fissure-hole combined flaws under uniaxial compression. Geosci. J. 2010, 22, 825-842. [CrossRef]

32. Tian, J.J.; Xu, D.J.; Liu, T.H. An experimental investigation of the fracturing behaviour of rock-like materials containing two V-shaped parallelogram flaws. Int. J. Min. Sci. Technol. 2020, 30, 777-783. [CrossRef]

33. Gong, F.Q.; Yan, J.Y.; Luo, S.; Li, X.B. Investigation on the linear energy storage and dissipation laws of rock materials under uniaxial compression. Rock Mech. Rock Eng. 2019, 52, 4237-4255. [CrossRef]

34. Zhang, Z.P.; Xie, H.P.; Zhang, R.; Zhang, Z.T.; Gao, M.Z.; Jia, Z.Q.; Xie, J. Deformation damage and energy evolution characteristics of coal at different depths. Rock Mech. Rock Eng. 2019, 52, 1491-1503. [CrossRef]

35. Yang, S.; Wang, J.; Ning, J.G.; Qiu, P.Q. Experimental study on mechanical properties, failure behavior and energy evolution of different coal-rock combined specimens. Appl. Sci. 2019, 9, 4427. [CrossRef]

36. Cheng, Z.Q.; He, C.; Wu, D.; Xu, G.W.; Yang, W.B. Fracture evolution and energy mechanism of deep-buried carbonaceous slate. Acta Geotech. 2017, 12, 1243-1260. [CrossRef]

37. Zhu, Z.N.; Tian, H.; Wang, R.; Jiang, G.S.; Dou, B.; Mei, G. Statistical thermal damage constitutive model of rocks based on Weibull distribution. Arab. J. Geosci. 2021, 14, 495. [CrossRef]

38. Wang, P.; Xu, J.Y.; Fang, X.Y.; Wang, P.X. Energy dissipation and damage evolution analyses for the dynamic compression failure process of red-sandstone after freeze-thaw cycles. Eng. Geol. 2017, 221, 104-113. [CrossRef]

39. Zhou, C.T.; Zhang, K.; Wang, H.B.; Xu, Y.X. A plastic strain based statistical damage model for brittle to ductile behaviour of rocks. Geomech. Eng. 2020, 21, 349-356. 